\title{
Electromagnetic Energy Harvester and Energy Storage System for Bike Lighting Applications
}

\author{
Yong-Nong Chang, ${ }^{1}$ Hung-Liang Cheng, ${ }^{2 *}$ Shun-Yu Chan, ${ }^{3}$ and Lin-Hsuan Huang ${ }^{1}$ \\ ${ }^{1}$ Department of Electrical Engineering, National Formosa University, Hu-Wei, Yunlin 63201, Taiwan \\ ${ }^{2}$ Department of Electrical Engineering, I-Shou University, Kaohsiung 84001, Taiwan \\ ${ }^{3}$ Department of Electrical Engineering, Cheng Shiu University, Kaohsiung 83347, Taiwan
}

(Received October 23, 2017; accepted January 29, 2018)

Keywords: electromagnetic energy harvester, uninterruptible energy storage circuit, lighting applications

In this work, we propose an electromagnetic energy harvester and energy storage system for bike lighting applications. On the basis of an energy harvester technique, an electromagnetic mechanism will be designed to drive light-emitting diodes (LEDs). The circuit framework, which comprises an electromagnetic energy harvester, an energy storage capacitor, a boost controller and lighting LEDs, is a kind of wireless sensors network (WSN). This novel design has the following features: (1) the LED is driven via an electromagnetic mechanism without the need for an external power source or battery, (2) an ultracapacitor is used as an energy storage device to deposit induction energy when the bicycle is moving, and (3) power is uninterruptible because electric energy accumulated on the ultracapacitor is supplied to the LED when the bicycle is stopped. In order to verify the feasibility of the proposed bike lighting applications, a prototype electromagnetic energy harvester with the electronic circuit is installed and tested on a bicycle. The experimental results indicate a satisfactory performance. The LED is effectively lit whether the bicycle is moving or at rest.

\section{Introduction}

In recent years, cycling has become increasingly popular in Taiwan. The safety of nighttime cycling greatly relies on lighting equipment. Therefore, installing a proper lighting set on a bicycle is indispensable. However, the current lighting devices for bicycles are mostly powered by batteries. The vast usage of batteries could lead to pollution while battery leakage could cause further environmental damage. Thus, the use of an energy harvester has become another solution to address this problem. ${ }^{(1-3)}$

The energy harvester can be categorized into three types, namely, electromagnetic, piezoelectric, and electrostatic/capacitive. All of them convert kinetic energy harvested from human movements, vehicle motion, and even the vibration of the earth. Although the piezoelectric energy harvester is the most well-developed structure with microelectromechanical systems (MEMS) compatibility, the electric charge leakage problem and poor

*Corresponding author: e-mail: hlcheng@isu.edu.tw http://dx.doi.org/10.18494/SAM.2018.1782 
coupling effect of piezoelectric elements lead to both poor conversion efficiency and reduced generating efficacy. Moreover, piezoelectric devices usually generate voltage by moving up and down and are not suitable for use as energy harvesters for bicycles. On the other hand, the electrostatic/capacitive energy harvester requires no highly sophisticated materials. However, the extra power source or charger requirement and mechanical limitation have constrained its application. ${ }^{(4-8)}$ This means that such devices must use an additional power source to generate electricity, which contradicts the concept of designing a bicycle lighting system without using additional voltage sources, such as batteries. In comparison with the electrostatic/capacitive and piezoelectric energy harvesters, the electromagnetic type, although it has a pick-up coil, bulky magnets, and MEMS integration problems, requires no sophisticated materials and no extra power source and is free of battery leakage. Therefore, it possesses the advantages of better generation efficiency and easy design. ${ }^{(9,10)}$

With regard to induction-type lighting equipment, few possess an energy storage feature other than a battery. Therefore, in this work, an ultracapacitor incorporated within a control circuit is developed to constitute a circuit with an uninterruptible power supply (UPS) function. Compared with the commonly used capacitors, the ultracapacitor can have on the order of $10^{4}$ recharge recycles and a short charging time. ${ }^{(11-13)}$ Thus, the developed bike lighting equipment can supply sufficient power to a light-emitting diode (LED) when the bike is moving or at rest. Moreover, the absence of a battery makes this induction generator mechanism environmentally friendly and energy efficient. Moreover, the successively developed energy harvesting technology can improve the performance of electronic apparatuses using energy harvesting techniques.

In this paper, a bike lighting system consisting mainly of an electromagnetic energy harvester, an ultracapacitor, three LEDs and a boost controller is built and tested. The experimental results indicate that satisfactory performance is achieved.

\section{Electromagnetic Energy Harvester and Energy Storage System Circuit}

Figure 1 shows the proposed circuit structure, which is grouped into two parts. After converting mechanical energy from the bike wheel to electric energy via an electromagnetic mechanism, the power is supplied to an energy storage capacitor $\mathrm{C}_{\mathrm{ultra}}$ along with one overvoltage protection Zener diode $\mathrm{ZD}_{1}$ and a boost controller circuit.

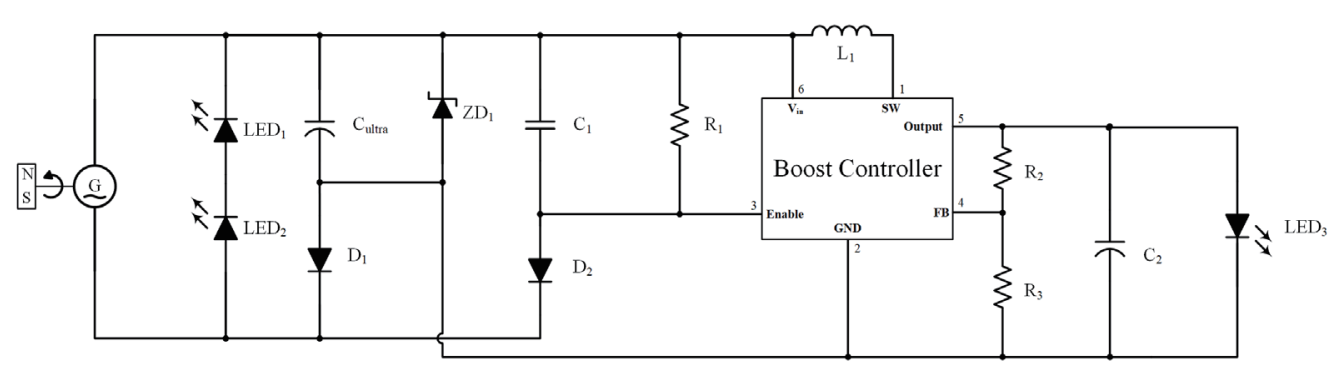

Fig. 1. Proposed circuit. 


\subsection{Electromagnetic energy harvester}

Figure 2 shows the schematic of the induction generator used in this study. The electromagnetic mechanism consists of one external magnet (the upper magnet in Fig. 2) and one internal magnet (the lower magnet in Fig. 2). Figure 3 shows the proposed electromagnetic energy harvester with the dimensions $1.8 \times 1.3 \times 1.8 \mathrm{~cm}^{3}$. The induction coils are wounded around the plastic holder embracing the internal magnet. All components are mounted on the front fork of the bicycle near the metallic rim of the wheel. When the wheel moves, a magnetic field in the metallic rim will be generated as a result of the relative movement between the external magnet and the rim. A magnetic force between the external magnet and the metallic rim is induced and drives the external magnet to rotate. Successively, the internal magnet is driven to rotate by the magnetic force generated by the interaction between the magnetic fields from the external and internal magnets. The rotation of the internal magnet produces a change in magnetic flux on the coils wound around the internal magnet. In this manner, an AC voltage would be induced on the coils. The generated AC voltage is taken and fed to the control circuit shown in Fig. 1, thus driving the LEDs.

\subsection{UPS energy storage circuit}

To achieve the UPS feature, the ultracapacitor (also called the electrical double-layer capacitor, EDLC) is selected as the energy storage device. Firstly, the change in electric charge on the capacitor is proportional to the change in voltage expressed by

$$
\Delta Q=\int_{t_{0}}^{t_{1}} i(t) d t=C_{u l t r a} \times\left[v_{c}\left(t_{1}\right)-v_{c}\left(t_{0}\right)\right]=C_{u l t r a} \times \Delta V .
$$

Here, $\Delta Q$ is the charge variation on the ultracapacitor, $i(t)$ is the discharging current, $C_{\text {ultra }}$ is the capacitance of the energy storage capacitor, $v_{c}\left(t_{0}\right)$ is the initial voltage of the capacitor, $v_{c}\left(t_{1}\right)$ is the instant voltage on the ultracapacitor at $t_{1}$, and $\Delta V$ is the voltage change on the ultracapacitor,

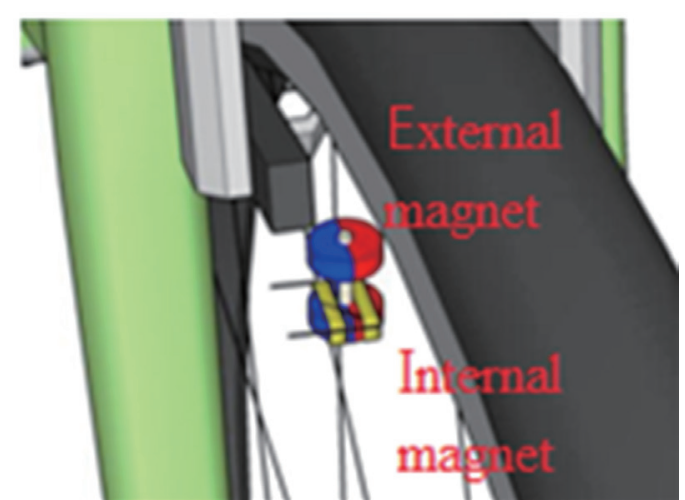

Fig. 2. (Color online) Schematic of the electromagnetic energy harvester.

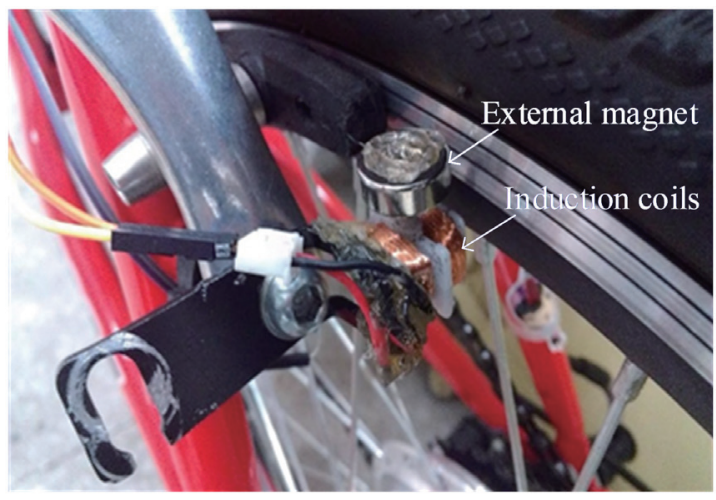

Fig. 3. (Color online) The proposed electromagnetic energy harvester. 
which is equal to the voltage difference between $v_{c}\left(t_{1}\right)$ and $v_{c}\left(t_{0}\right)$.

The average current $I_{\text {avg }}$ of the ultracapacitor in the discharging period is defined as

$$
I_{\text {avg }}=\frac{\int_{t_{0}}^{t_{1}} i(t) d t}{t_{1}-t_{0}}=\frac{\int_{t_{0}}^{t_{1}} i(t) d t}{\Delta t},
$$

where $\Delta t$ is the discharge time of the energy storage capacitor.

By substituting Eq. (2) into Eq. (1), it yields Eq. (3), which is used to evaluate the discharging time of the energy storage capacitor.

$$
\Delta t=\frac{C_{u l t r a} \times \Delta V}{I_{a v g}}
$$

Owing to the size restriction and bike speed, the magnitude of the generated voltage is very small. The amount of change in electric charge is affected by $\Delta V$. To increase the voltage change to an acceptable magnitude, a boost controller is incorporated into the UPS circuit. By boosting the voltage change from the ultracapacitor, the circuit could exhibit constant-current operation and thus, can supply power to $\mathrm{LED}_{3}$ uninterruptedly.

\section{Description of Operation Modes}

To make the operation principle of the developed system easily understandable, the circuit operation principle can be described by the following 4 modes.

\subsection{Mode I}

When the bike is moving, the induction-type generator supplies an $\mathrm{AC}$ voltage. Figure 4 shows the polarity of the generated voltage and the path of the LED current when the AC voltage is in the negative half-cycle. $\mathrm{LED}_{1}$ and $\mathrm{LED}_{2}$ are on to light the way for the rider. If

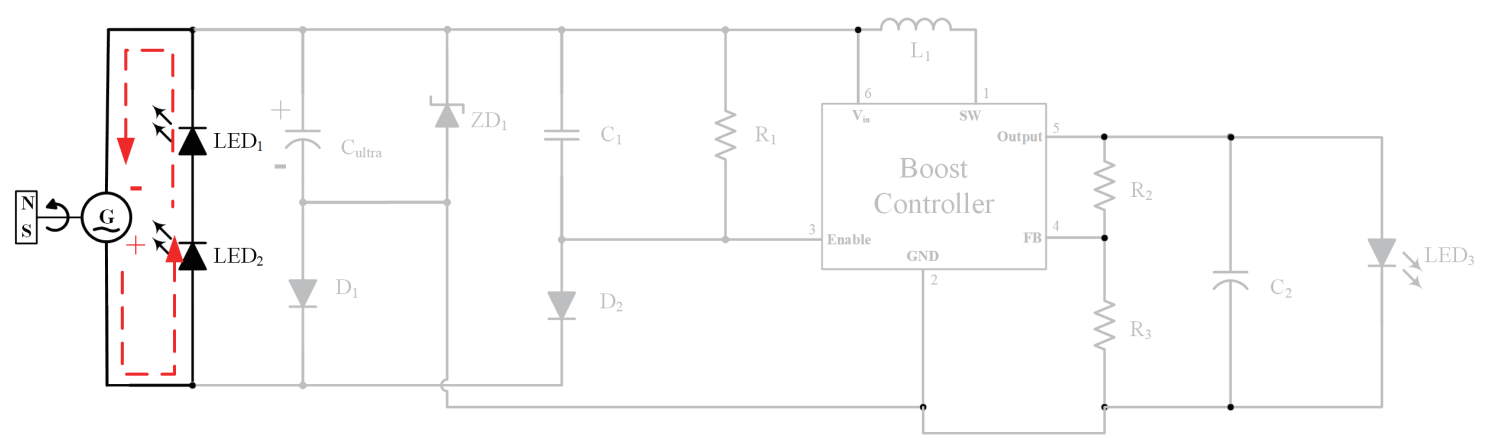

Fig. 4. (Color online) Mode I. 
the bike keeps on moving, the electromagnetic energy harvester continues to generate voltage. When the polarity of the AC voltage changes, Mode II follows.

\subsection{Mode II}

Figure 5 shows voltage polarity and the current paths when the $\mathrm{AC}$ voltage is in the positive half-cycle. The current flows through diodes $\mathrm{D}_{1}$ and $\mathrm{D}_{2}$ and resistor $\mathrm{R}_{1}$ while the energy storage capacitor $\mathrm{C}_{\mathrm{ultra}}$ and capacitor $\mathrm{C}_{1}$ are being charged. Modes I and II will alternate until the bike stops. As the bike stops, the energy harvester no longer creates voltage and Mode III comes into play.

\subsection{Mode III}

When the bike comes to a standstill, the electromagnetic energy harvester produces no voltage and the boost controller IC is disabled. The only current path is shown in Fig. 6; the energy stored in the capacitor $C_{1}$ will be released to resistor $R_{1}$. When the energy of $C_{1}$ is fully discharged, the $V_{\text {in }}$ pin and Enable pin of the boost controller IC are in phase. The boost controller IC is activated and Mode IV starts.

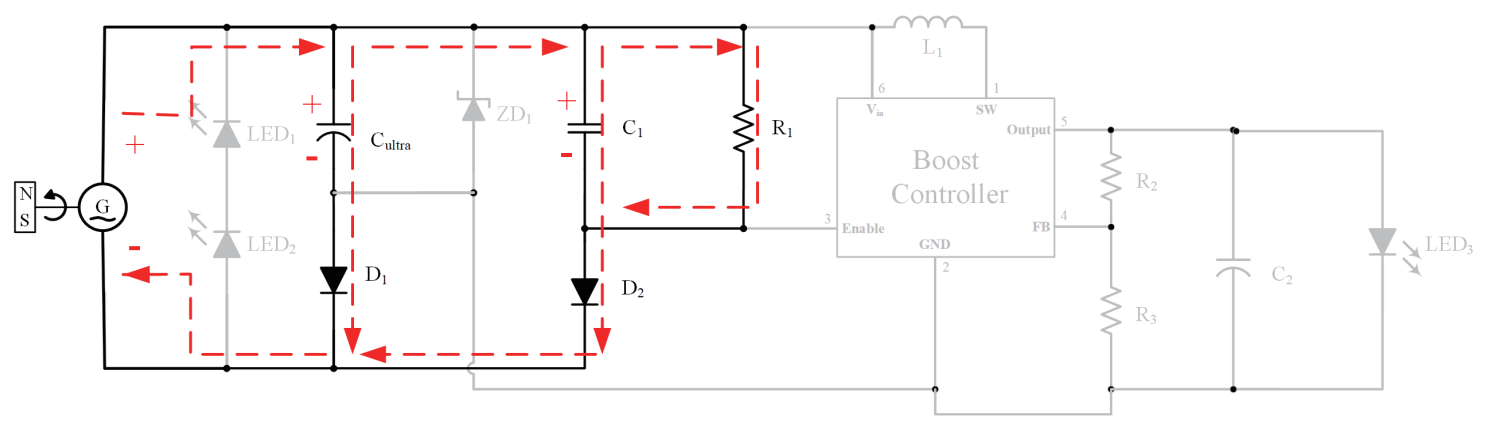

Fig. 5. (Color online) Mode II.

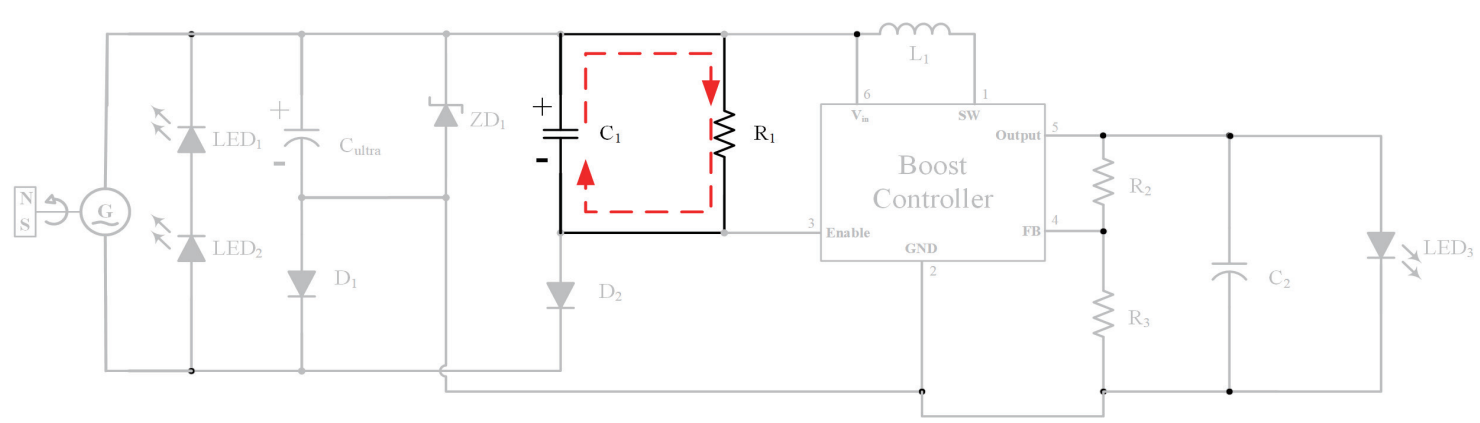

Fig. 6. (Color online) Mode III. 


\subsection{Mode IV}

After the end of Mode III, Mode IV comes into play as shown in Fig. 7. In Mode IV, the electric charge on $\mathrm{C}_{1}$ is fully discharged and the voltage $V_{C 1}$ falls to zero. Meanwhile, the energy storage capacitor $C_{\text {ultra }}$ supplies voltage to the drive boost controller. As soon as the boost controller is activated, the boost inductor $\mathrm{L}_{1}$ is employed to boost the voltage change from $\mathrm{C}_{\mathrm{ultra}}$, the resistors $\mathrm{R}_{2}$ and $\mathrm{R}_{3}$ constitute a voltage divider to feed back the output voltage to pin 4 (FB) of the boost controller IC, and $\mathrm{C}_{2}$ serves as a voltage stabilizer to drive $\mathrm{LED}_{3}$. When the voltage $V_{\text {Cultra }}$ across $\mathrm{C}_{\text {ultra }}$ is smaller than the minimum working voltage of the boost controller, the operation returns to Modes I and II.

\section{Test and Performance of Developed Lighting Circuit}

To measure the performance of the proposed electromagnetic energy harvester, a test platform was built. First, the bike was driven by a DC motor to charge the ultracapacitor for a period of time. Then, the motor stopped and the ultracapacitor discharged energy to light the LEDs via the boost controller. The charge and discharge times of the ultracapacitor were measured and are shown in Table 1. As soon as the induction generator was mounted on the bike, the bike was driven at 20 and $30 \mathrm{~km} / \mathrm{h}$. The ultracapacitor was charged for $60,120,180$, and $240 \mathrm{~s}$.

Figure 8 shows that when the bike is driven at a speed of $20 \mathrm{~km} / \mathrm{h}$, the $450 \mathrm{~s}$ charge time can accumulate energy in the ultracapacitor sufficient for $250 \mathrm{~s}$ of $\mathrm{LED}_{3}$ lighting time. Figure 9 shows that at $30 \mathrm{~km} / \mathrm{h}$, the $250 \mathrm{~s}$ charge time can accumulate energy in the ultracapacitor sufficient for $350 \mathrm{~s}$ of $\mathrm{LED}_{3}$ lighting time.

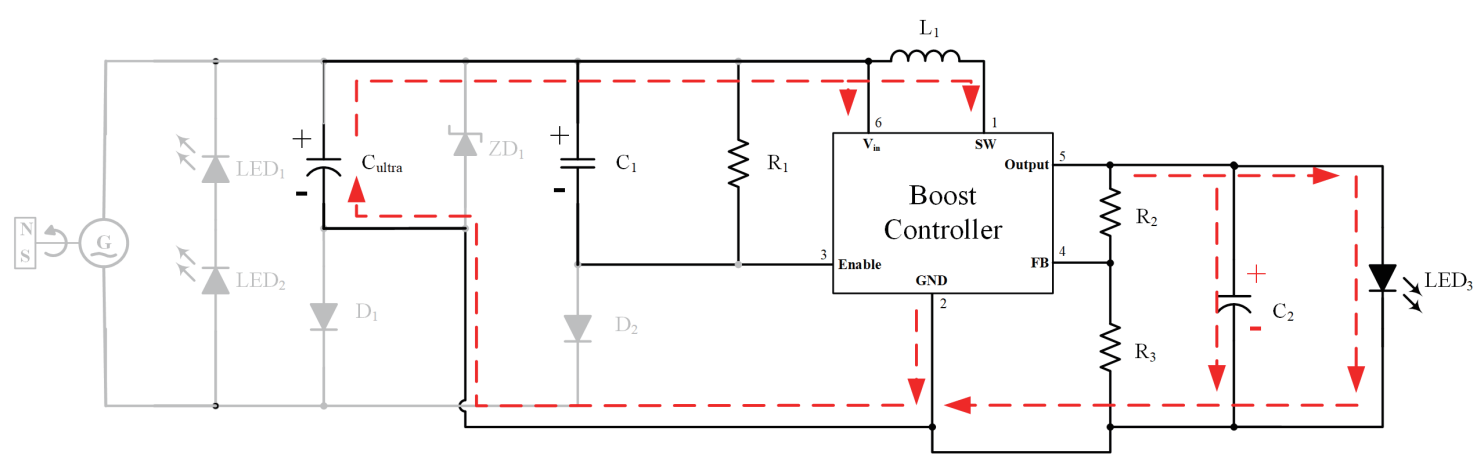

Fig. 7. (Color online) Mode IV.

Table 1

Charge/discharge times corresponding to 20 and $30 \mathrm{~km} / \mathrm{h}$.

\begin{tabular}{|c|c|c|c|}
\hline \multicolumn{2}{|c|}{$20 \mathrm{~km} / \mathrm{h}$} & \multicolumn{2}{|c|}{$30 \mathrm{~km} / \mathrm{h}$} \\
\hline $\begin{array}{l}\text { Riding time (s) } \\
\text { (charge) }\end{array}$ & $\begin{array}{c}\text { Lighting time }{ }^{*}-\mathrm{LED}_{3}(\mathrm{~s}) \\
\text { (discharge) }\end{array}$ & $\begin{array}{l}\text { Riding time (s) } \\
\text { (charge) }\end{array}$ & $\begin{array}{c}\text { Lighting time }{ }^{*}-\mathrm{LED}_{3}(\mathrm{~s}) \\
\text { (discharge) }\end{array}$ \\
\hline 60 & 55 & 60 & 90 \\
\hline 120 & 104 & 120 & 234 \\
\hline 180 & 155 & 180 & 307 \\
\hline 240 & 188 & 240 & 340 \\
\hline
\end{tabular}

*Lighting time is when the bike is stopped after riding. 


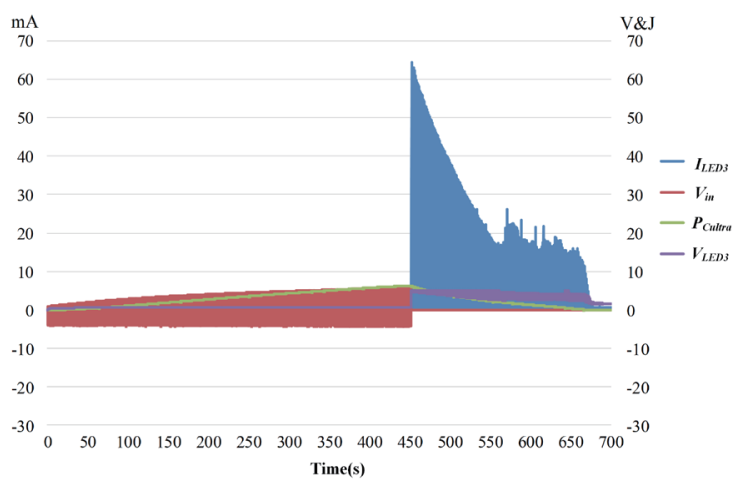

Fig. 8. (Color online) $20 \mathrm{~km} / \mathrm{h}$ charge/discharge curve (charge time $450 \mathrm{~s}$ ).

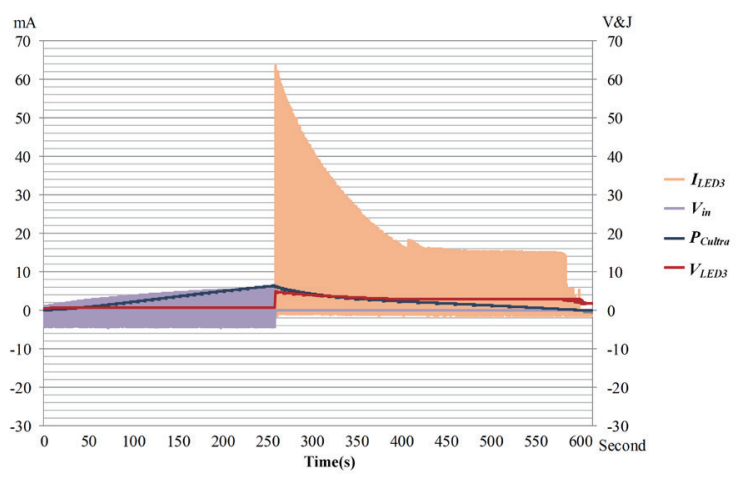

Fig. 9. (Color online) $30 \mathrm{~km} / \mathrm{h}$ charge/discharge curve (charge time $250 \mathrm{~s}$ ).

\section{Conclusions}

In this study, the ultracapacitor was introduced along with an electromagnetic energy harvester to furnish the lighting circuit with electricity storage capability. The realized circuit could, therefore, power the LED incessantly. By the energy harvesting technique, the energy storage component can power the bike LEDs interminably. The realized installation and tests revealed that the developed bike lighting system can continually power the LEDs regardless of whether the bike is moving or at rest.

The performance of the developed bike lighting set is superior to those of existing bike lighting products. With the advantage of simple structure, the developed bike lighting set can elicit a willingness in consumers to use it. The compact and simple design will provide riders with a simple and reliable bike lighting system. Moreover, it can effectively eliminate ecologically harmful battery usage and meet the criteria of green energy policy.

\section{References}

1 Y. H. Song, S. D. Ko, and J. B. Yoon: J. Microelectromech. Syst. 24 (2015) 1495.

2 A. Tanaka, T. Douseki, Y. Umeki, H. Kawaguchi, M. Yoshimoto, K. Tsunoda, and T. Sugii: Proc. 2015 IEEE Sensors (IEEE 2015) 1-4.

3 H. Liu, Y. Xia, T. Chen, Z. Yang, W. Liu, P. Wang, and L. Sun: IEEE Sens. J. 17 (2017) 3853.

4 T. Galchev, H. Kim, and K. Najafi: J. Microelectromech. Syst. 20 (2011) 852.

5 E. Bouendeu, A. Greiner, P. J. Smith, and J. G. Korvink: J. Microelectromech. Syst. 20 (2011) 466.

6 Ö. Zorlu, E. T. Topal, and H. Külah: IEEE Sens. J. 11 (2011) 481.

7 H. Liu, Z. Ji, T. Chen, L. Sun, S. C. Menon, and C. Lee: IEEE Sens. J. 15 (2015) 4782.

8 A. Ostadi, M. Kazerani, and S. K. Chen: Proc. 2013 IEEE Transportation Electrification Conf. and Expo (IEEE 2013) 1-7.

9 Y. Choi, S. Ju, S. H. Chae, S. Jun, and C. H. Ji: Smart Mater. Struct. J. IOPscience 24 (2015) 1.

10 C. Zeng, H. Lian, T. Chen, Z. Cai, and D. Fang: 2016 31st Youth Academic Annu. Conf. Chinese Association of Automation (2016) 399-402.

11 P. J. Grbović, P. Delarue, and P. L. Moigne: Proc. 2012 IEEE 7th Power Electronics and Motion Control Conf. (IEEE 2012) 771-777.

12 S. Ahmed and V. Kakkar: IEEE Access 5 (2017) 19631.

13 A. Khaligh, P. Zeng, and C. Zeng: IEEE Trans. Ind. Electron. 57 (2010) 850. 